\title{
The Price we Pay for Overdose of Antibiotics: Is there any Alternative?
}

\author{
PD Gupta ${ }^{1 *}$ and AK Asha ${ }^{2}$ \\ ${ }^{1}$ Gujarat University, India \\ ${ }^{2}$ Department of Microbiology, Bhartiyar University, India \\ *Corresponding author: PD Gupta, Professor Adjunct, Gujarat University, Ahmadabad, Gujarat, India
}

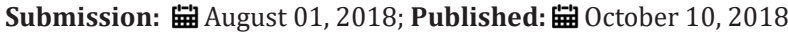

\begin{abstract}
To take care of health issues of next generation we must stop the use of antibiotics. However, we must find the ways and means to control the bacterial infection of present population. Here in this review we described some of the novel methods and their mode of action to protect the present inhabitants
\end{abstract}

\section{Introduction}

More and more antibiotics becoming useless; many bacterial species have become drug resistant because of overdose of these drugs [1]. Not just because of only drug resistance, even imbalance of bacterial strains in microbiota can be the cause of serious health issues [2]. We must rebuild our defenses against deadly bacteria. Do we have any alternatives to existing antibiotics?

\section{Approaches towards Elimination of Antibiotics}

Recently researchers have found some alternatives to attack bacteria without using antibiotics.

\section{Genetical approach}

This approach is very effective. The bacterial genetic material (DNA and/or RNA) is attacked by synthetic peptide-conjugated phosphorodiamidate morpholino oligomer (PPMO) [3]. This compound has been proved to be the bacteria's new worst enemy; even superbug Clostridium difficile is killed by this newly synthesized compound. Unlike antibiotics, PPMO can silence specific genetic targets by disrupting

the bacterial gene's synthesizing capacity. Although, there is no issues about the efficacy of PPMO, issues of its toxicity need to be addressed in further testing before it can be used in humans. The mechanism that PPMOs use to kill bacteria is revolutionary and therefore bacteria can not develop resistance to this; as they have developed for conventional antibiotics [4].

\section{Viral attack}

Superbug Clostridium difficile is one of the natural microbes found in the gut, but chronic antibiotic use can make it go haywire. It's also one of the many superbugs turning up at hospitals. It caus es many deaths and hospitalizations among humans worldwide. Specialists at the University of Leicester and AmpliPhi Biosciences
Corporation have found phages, viruses that eat bacteria, to specifically target $\mathrm{C}$. diff. They work by attaching to bacteria as a host, injecting their DNA-which replicates-and causing the bacterial cell to burst open. Researchers say these phages are effective against 90 percent of the most clinically relevant C. diff strains in the United Kingdom.

"The key advantage of using phages over antibiotics lies in their specificity. A phage will infect and kill only a specific strain or species of bacteria. This is particularly important when treating conditions like C. diff infections, where maintenance of the natural balance of gut bacteria greatly reduces the chance of relapse," Dr. Martha Clokie, from the University of Leicester's Department of Infection, Immunity and Inflammation, said in a statement. AmpliPhi is funding the development of these C. diff phages and hopes to have a mixture ready for clinical trials soon [5].

\section{Fecal microbiota transplant}

Fecal microbiota transplant (FMT) is the process of transplantation of fecal bacteria from a healthy individual into a recipient. FMT involves restoration of the colonic microflora by introducing healthy bacterial flora through infusion of stool, e.g. by enema, orogastric tubeor by mouth in the form of a capsule containing freezedried material, obtained from a healthy donor [6,7]. FMT has been used experimentally to treat other gastrointestinal diseases, including colitis constipation, irritable bowel syndrome, and neurological conditions such as multiple sclerosis and Parkinson's by removing imbalance of gut microbiota [2]. A limited number of studies have shown it to be an effective treatment for patients suffering from Clostridium difficile infection (CDI), whose effects can range from diarrhea to pseudomembranous colitis. The mechanism of action of fecal microbiota transplant works by restoring the imbalance $[2,8,9]$. 

A. Bacterial interference
B. The restoration of missing components of the flora
C. Production of antimicrobial agents (Bacteriocins)

\section{Nanotechnologal approach}

Nanoparticles are increasingly used to target bacteria as an alternative to antibiotics. Nanoscience can offer various accurate, economical and less time-consuming methods, which will help to avert microbial spread and its consequences. The antibacterial activity of nanoparticles is poorly understood; however, currently accepted mechanisms include oxidative stress induction, metal ion release, and non-oxidative mechanism. The multiple simultaneous mechanisms of action against microbes would produce multiple simultaneous gene mutations in the same bacterial cell for antibacterial resistance to develop (Figure 1).

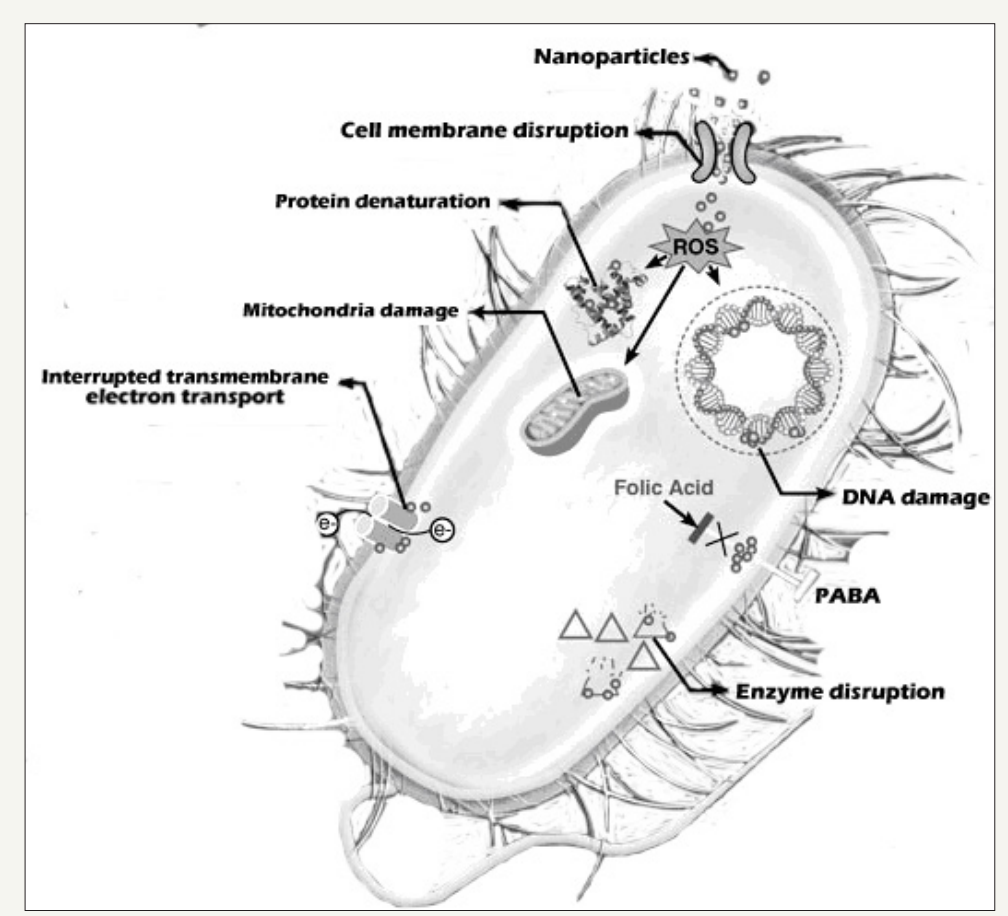

Figure 1: Showing various mechanism of action of bactericidal drugs.

Therefore, it is difficult for bacterial cells to become resistant to nanoparticles [10]. A team of researchers from Jackson State University, USA has developed a new popcorn-shaped ironmagnetic core gold plasmonic shell nanoparticles for surfaceenhanced Raman spectroscopy (SERS) detection and photothermal destruction of multiple drug resistant (MDR) Salmonella bacteria. They have also reported that the same core-shell nanoparticle can be used in combination with near infrared (NIR) light to form lightdirected nanoheaters for hyperthermic destruction of MDR [11]. Silver has been used as an antimicrobial agent for more than 100 years, however, now silver nanoparticles are even incorporated in such products as plastic food containers, medical materials, and clothing just to fight with bacteria [12].

\section{References}

1. Higgins CF (2007) Multiple molecular mechanisms for multidrug resistance transporters. Nature 446(7137): 749-757.

2. Sawicka B, Johar K, Sood PP, Gupta PD (2017) Imbalance of gut microbiota induces cancer. J Cell Tissue Res 17(2): 6073-6084.

3. Oregon State University (2013) Beyond antibiotics: 'PPMOs' offer new approach to bacterial infection, other diseases. Science Daily, USA.
4. Bruce LG, Kimberly MB, Frederick JS, Mattie MM, Patrick LI, et al. (2013) Gene-silencing antisense oligomers inhibit Acinetobacter growth in vitro and in vivo. J Infec Diseases.

5. Janet YN, Janice S, Katherine RH, Anthony MB, Przemysław T, et al. (2016) Bacteriophage combinations significantly reduce clostridium difficile growth in vitro and proliferation in vivo. Antimicrobial Agents and Chemotherapy 60(2): 968.

6. Drekonja D, Reich J, Gezahegn S, Greer N, Shaukat A, et al. (2015) Fecal microbiota transplantation for clostridium difficile infection. A systematic review. Annals of Internal Medicine 162(9): 630-638.

7. Smith PA (2014) A new kind of transplant bank. The New York Times, USA.

8. Chang JY, Antopoulos DA, Kalra A (2008) Decreased diversity of the fecal microbiome in recurrent Clostridium difficile-associated diarrhea. J Infect Dis 197(3): 435-438.

9. Khoruts A, Dicksved J, Jansson JK (2010) Changes in the composition of the human fecal microbiome after bacteriotherapy for recurrent Clostridium difficile-associated diarrhea. J Clin Gastroenterol 44(5): 354-360.

10. Linlin W, Chen H, Longquan S (2017) The antimicrobial activity of nanoparticles: present situation and prospects for the future. Int J Nanomedicine 12: 1227-1249. 
11. Fan Z, Senapati D, Khan SA, Ray PC (2013) Popcorn-shaped magnetic core plasmonic shell multifunctional nanoparticles for the targeted magnetic separation and enrichment, label-free SERS imaging, and photothermal destruction of multidrug-resistant bacteria. Chem Eur J 19(8): 2839-2847.
12. Nam S, Brian DC, Christopher DD, Krystal RF (2016) Silver-cotton nanocomposites: Nano-design of microfibrillar structure causes morphological changes and increased tenacity. Scientific Reports 6, Article number: 37320.

\section{For possible submissions Click Here Submit Article}

\begin{tabular}{|l} 
COJ Technical \& Scientific Research \\
Benefits of Publishing with us
\end{tabular}

